\title{
Over or under? Autonomous sensor fish reveals why overshot weirs may be safer than undershot weirs for fish passage
}

\author{
Brett D. Pflugrath ${ }^{\mathrm{a}, \mathrm{b}, \mathrm{d}, *}$, Craig A. Boys ${ }^{\mathrm{a}, \mathrm{c}}$, Bruce Cathers ${ }^{\mathrm{b}}$, Zhiqun Daniel Deng ${ }^{\mathrm{d}, \mathrm{e}}$ \\ ${ }^{a}$ New South Wales Department of Primary Industries, Port Stephens Fisheries Institute, Taylors Beach, NSW, Australia \\ ${ }^{\mathrm{b}}$ Water Research Laboratory, School of Civil and Environmental Engineering, University of New South Wales, Manly Vale, Sydney, NSW, Australia \\ ' Institute of Land, Water and Society, Charles Sturt University, Albury, NSW, Australia \\ ${ }^{\mathrm{d}}$ Pacific Northwest National Laboratory, Richland, WA, USA \\ ${ }^{\mathrm{e}}$ Department of Mechanical Engineering, Virginia Tech, Blacksburg, VA, USA
}

\section{A R T I C L E I N F O}

\section{Keywords:}

Weir

Overshot

Undershot

Sluice gate

Fish passage

Strike

Shear

Decompression

\begin{abstract}
A B S T R A C T
Many riverine fish species disperse downstream as eggs, juveniles, or adults, which can expose them to injury and death at hydraulic structures. Low-head weirs are one example of a structure that can kill fish, and this impact has been shown to be substantially higher for undershot weirs when compared to overshot weirs. In this study, autonomous sensor devices were released at an overshot and undershot weir under similar discharges to assess what stressors maybe contributing to differences in the survival rates of fish. Although the undershot weir was more likely to expose fish to rapid decompression, the intensity of decompression was mild and it is more likely that higher levels of fluid shear at the undershot are more damaging to early life stage and small-bodied fish. Both weirs showed potential for strike, but this could be managed through improvements in design.
\end{abstract}

\section{Introduction}

Hydraulic structures, such as hydropower dams and weirs, greatly assist in the management of water resources and the production of hydropower, but can also have detrimental effects on freshwater fish populations (Baumgartner et al., 2013; Boys et al., 2014; Boys et al., 2016a; Brown et al., 2012a; Čada, 1997). These structures can restrict or delay fish migration, increased predation, alter water quality, and directly cause stress, injury, or mortality (Schilt, 2007). One such source of stress, injury, and mortality is downstream passage at river infrastructure, where fish may be exposed to extreme hydraulic conditions.

Three hydraulic or physical conditions, which if sufficiently severe can cause injury to fish that migrate downstream past dams and weirs, include mechanical strike, shear forces, and rapid decompression (Čada, 2001). Strike occurs when fish collide with part of the structure (e.g. steel gates, turbine blades, or the downstream concrete apron). Strike can result in injuries such as descaling, gill and operculum damage, abrasions, eye damage, split fins, and bruising (Deng et al., 2005). Shear events occur when a fish passes through an interface of two water bodies moving at different velocities or in different directions. This can result in distortion or abrasion across the body of the fish (Deng et al., 2005), leading to injuries similar to those that occur by strike. Rapid decompression can cause gas bubbles to form within the blood and tissues of the fish and gas expansion in organs such as the swim bladder (Brown et al., 2012a; Brown et al., 2012b). When this occurs, there is potential for a fish to sustain barotrauma, which can result in death when severe (Brown et al., 2012a).

No two hydraulic structures are likely to have an identical stressor profile. To date, most evaluation of stressors has been on turbines and large dams, which are likely to generate extreme hydraulic conditions (Deng et al., 2010; Fu et al., 2016). However, even small weirs can create hydraulic conditions that harm fish (Baumgartner et al., 2013; Baumgartner et al., 2006; Marttin and De Graaf, 2002). Therefore, there is a clear need to understand the hydraulic condition that fish are exposed to at all structures, including smaller structures, such as low-head weirs.

There are two types of weirs commonly used in rivers, overshot (e.g. sharp-crested) and undershot (e.g. sluice), each with many variations. As the names imply, an overshot weir passes water over the top of a gate, whereas an undershot weir passes water under a gate. For lowhead structures, overshot weirs have been shown to be safer for fish than undershot weirs (Baumgartner et al., 2013; Baumgartner et al., 2006; Marttin and De Graaf, 2002). This is based on biological testing that found considerably higher mortality rates in larval fish passing an undershot weir compared to an overshot. However, it is not clear which

\footnotetext{
* Corresponding author at: Pacific Northwest National Laboratory, 902 Battelle Blvd, Richland, WA 99352, USA.

E-mail address: brett.pflugrath@pnnl.gov (B.D. Pflugrath).
} 


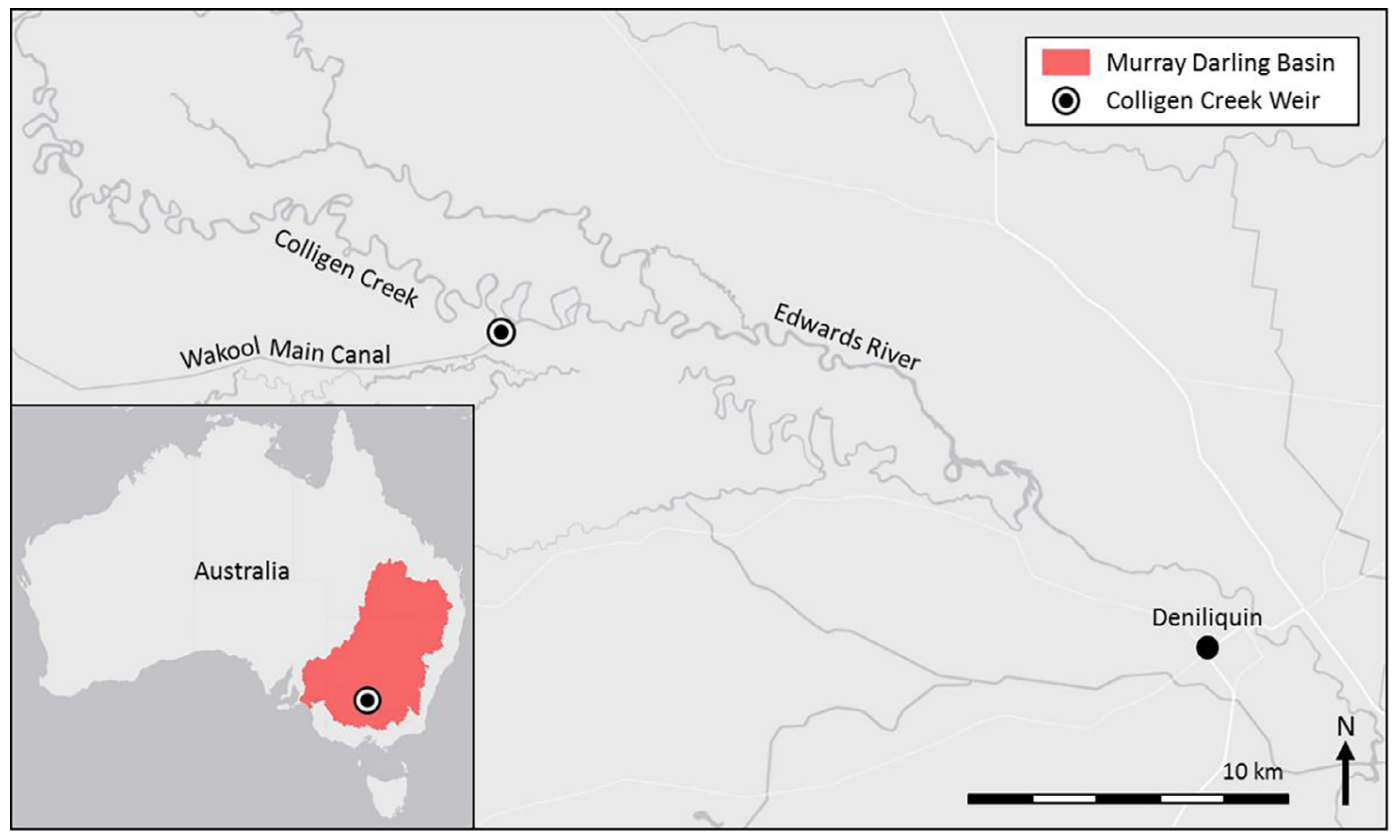

Fig. 1. Colligen Creek weir is located within the Murray Darling Basin in south eastern Australia, near Deniliquin NSW. Colligen Creek is a tributary of the Edwards River and delivers water to the Wakool Main Irrigation Canal.

stressors were responsible for the injuries sustained by fish (Baumgartner et al., 2013; Baumgartner et al., 2006; Marttin and De Graaf, 2002). Without such knowledge, it is difficult to determine whether simple design or operational changes may mitigate the impacts on fish. In this study, an autonomous sensor package was deployed in the field to determine which hydraulic conditions may be responsible for different survival results of fish passing overshot and undershot weirs.

\section{Material and methods}

Hydraulic conditions were measured at both an undershot and an overshot weir with a similar discharge at Colligen Creek Weir. Colligen Creek Weir is located on Colligen Creek, near Deniliquin, New South Wales Australia (Fig. 1). The weir enables water to be diverted from Colligen Creek into the Wakool Main Irrigation Canal and is comprised of seven undershot weirs, one overshot weir, and a fishway (Fig. 2). During this study, the overshot weir gate was operated at an inclination of $30^{\circ}$ to the horizontal, thereby placing the top of the weir $0.45 \mathrm{~m}$ below the upstream water surface (Fig. 3a). One of the seven undershot weirs was opened and was operated in a drowned state, meaning that the downstream water level was above the top of the weir gate opening (Fig. 3b).

Both the overshot and undershot weirs were operated to have a similar discharge of approximal $1.50 \mathrm{~m}^{3} \cdot \mathrm{s}^{-1}$ based on what was advised by the facility operator as a typical operational setting. After completing the testing, the discharge was calculated based on river heights measured at the facility and the gate setting. These calculations suggested a discharge of $1.51 \mathrm{~m}^{3} \cdot \mathrm{s}^{-1}$ past the overshot weir and $1.67 \mathrm{~m}^{3} \cdot \mathrm{s}^{-1}$ through the undershot weir. The following equations (1-4) were used to calculate the discharge at the weirs (Garde, 1997):

The discharge past an overshot weir $(Q)$ equation is given by:

$Q=\frac{2}{3} C_{d} B \sqrt{2 g} H^{3 / 2}$

where $B$ is the width of the weir gate, $g$ is gravitational acceleration, $H$ is upstream head relative to the top of the weir, and the discharge coefficient $\left(C_{d}\right)$ is given by:

$C_{d}=0.611+0.075(H / W)$ where $W$ is the height of the weir (Fig. 4).

The discharge through an undershot weir $(Q)$ is given by (see Fig. 5):

$Q=C_{d} B a \sqrt{2 g\left(H_{1}-H_{2}\right)}$

where $B$ is the width of the weir gate, $a$ is the gate opening, $g$ is gravitational acceleration, $H_{1}$ is the depth of flow upstream of the weir, $\mathrm{H}_{2}$ is depth of flow downstream of the weir and the discharge coefficient $\left(C_{d}\right)$ is given by:

$C_{d}=\frac{0.60}{\sqrt{1-\left(0.60 a / H_{1}\right)^{2}}}$

Hydraulic conditions within the two weirs were measured using the Gen 2 Sensor Fish (Deng et al., 2014; Hou et al., 2018) (Fig. 6). The sensor package measures pressure, temperature, and three dimensional measurements of linear acceleration, rotational velocities, and orientation, all recorded at a sampling frequency of $2048 \mathrm{~Hz}$ (Deng et al., 2014). The Sensor Fish has a diameter of $24.5 \mathrm{~mm}$, a length of $89.9 \mathrm{~mm}$, a mass of approximately $42.1 \mathrm{~g}$, and is nearly neutrally buoyant in fresh water. When deployed, the Sensor Fish is neutrally buoyant and after a predetermined time based on the time expected to travel through the region of interests, it becomes positively buoyant in order to navigate itself to the surface. Once at the surface, the Sensor Fish transmits a signal for localization and recovery. All Sensor Fish were painted florescent pink to provide visual contrast to aid recovery after deployment and the completion of measurements. A total to 12 deployments were conducted for both the overshot and undershot weirs (see Fig. 7).

Deployments were conducted by simply dropping a Sensor Fish into the water 1 to $2 \mathrm{~m}$ upstream of the weir and allowing it to be entrained past the weirs. Sensor Fish were retrieved downstream of the weir by boat and then brought back to shore for downloading the measurements.

Pressure scenarios were developed for each weir based on Sensor Fish measurements (all pressures reported as absolute pressure). The nadir (lowest) pressure, maximum pressure, and rate of decompression were determined for each deployment. Because the ratio of pressure change (ratio of acclimation pressure to nadir pressure) has been determined as a predictor of injury and mortality in fish exposed to rapid decompression (Boys et al., 2016a; Boys et al., 2016b; Brown et al., 


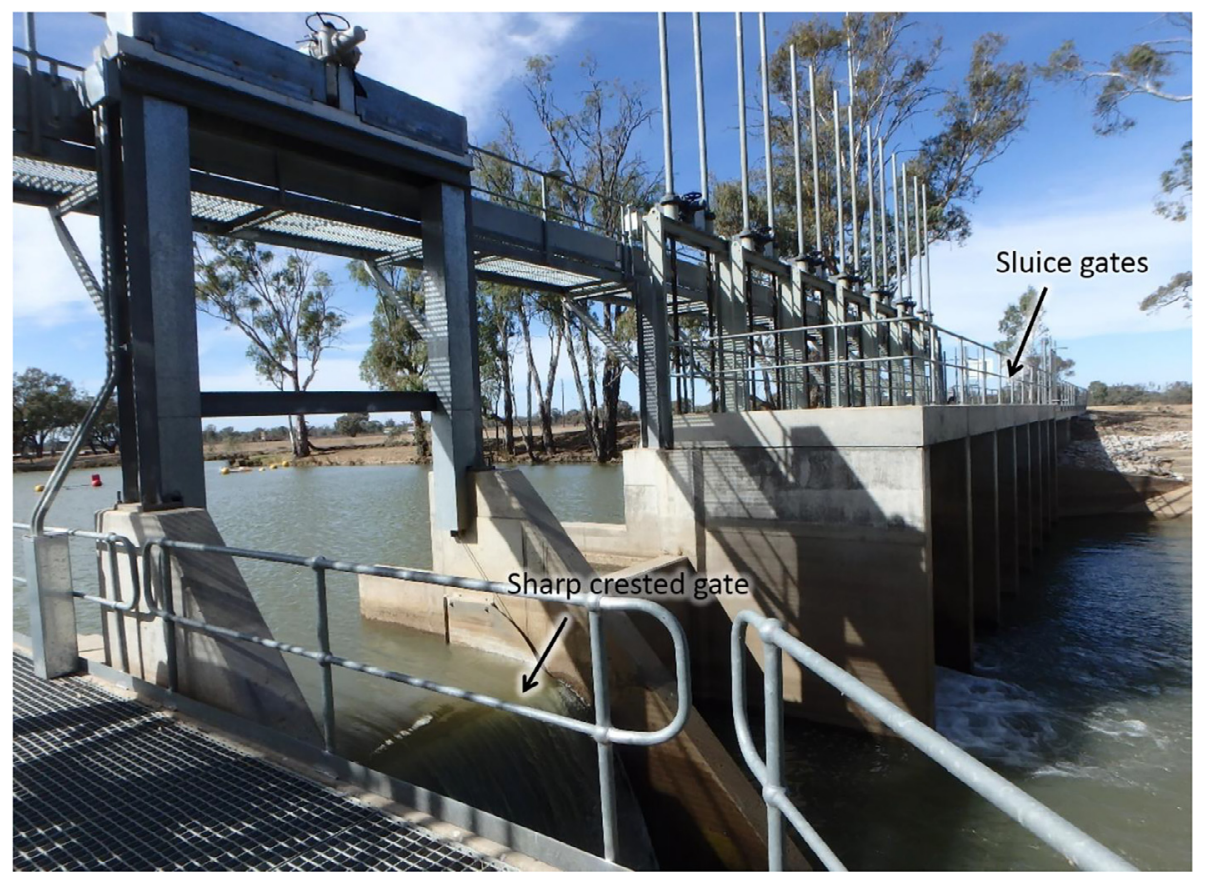

Fig. 2. Colligen Creek Weir with one overshot weir (left) and seven undershot weirs (right). The fishway is located to the left of the overshot weir.

2012a; Pflugrath et al., in press), the ratio of pressure change was calculated for all deployments. This was calculated using nadir pressures recorded by Sensor Fish and the maximum pressure that a fish could be acclimated to upstream of the weir. For the undershot weir, the maximum acclimation pressure was determined to be $125 \mathrm{kPa}$, which is the pressure present at the maximum channel depth immediately prior to the weir $(2.5 \mathrm{~m})$. For the weir, it was assumed that as a fish approaches the weir, in order to pass the structure, the fish must be near the water surface and, will therefore be surface acclimated (101.4 kPa during deployments) or at a state which is not likely to cause injury at that pressure.

Pressure measurements were also used to identify distinct characteristics of the structure and to estimate the location of strike and shear events. Strike and shear events were identified by high amplitude acceleration and rotational velocity impulses. Strike can be differentiated from shear based on the duration of the impulse; events with peak duration less than $0.0075 \mathrm{~s}$ are determined to be strike events and those longer than $0.0075 \mathrm{~s}$ are shear events (Deng et al., 2007) (Fig. 8).

(a)

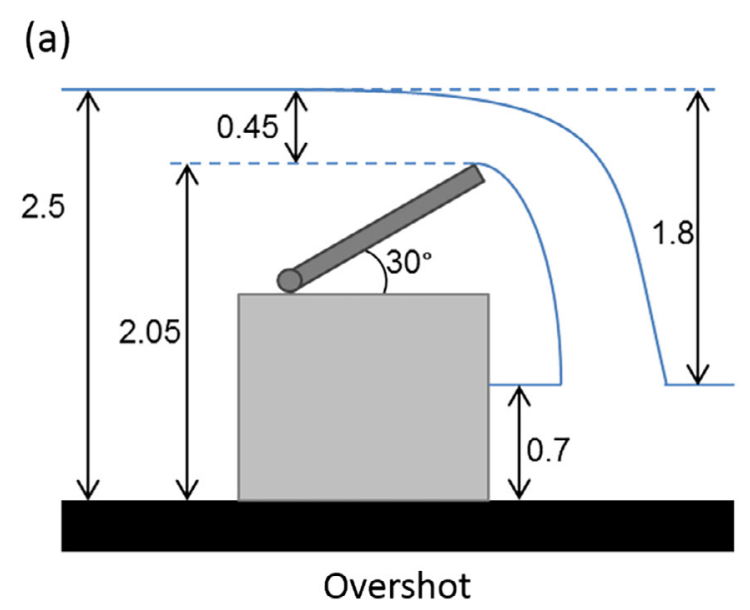

T-tests (two-sample assuming unequal variance) were performed to determine if there were differences between the overshot and undershot weirs for the mean values of maximum pressure, nadir pressure, ratio of pressure change, strike and shear severity, and the number of strike events. Fisher's exact test was used to evaluate the occurrence of multiple strike events recorded by Sensor Fish.

\section{Results}

\subsection{Pressure histories}

Very little change in pressure was measured as Sensor Fish passed the overshot weir (Fig. 9). This was because Sensor Fish were released near the surface of the water and only recorded a small pressurisation when entering the downstream plunge pool. After entering the plunge pool, Sensor Fish floated back to the surface.

Sensor Fish passing through the undershot weir recorded pressurisation to almost $125 \mathrm{kPa}$ (depth equivalent to $2.5 \mathrm{~m}$ ) prior to a rapid

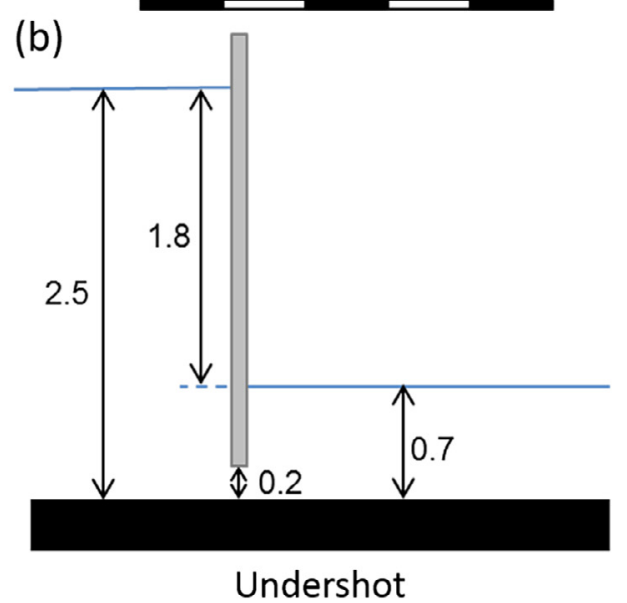

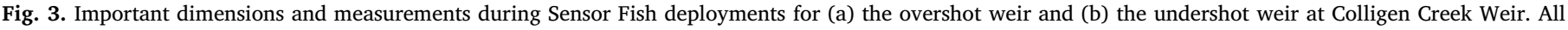
dimensions are in metres. 

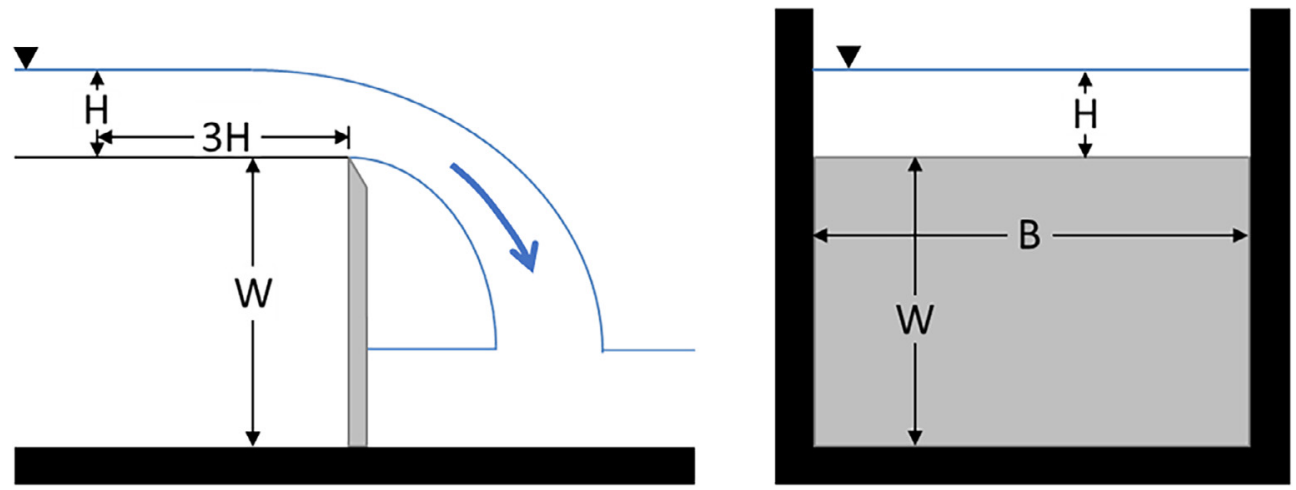

Fig. 4. Variables used in Eqs. (1) and (2) for calculating flow over the overshot weir.

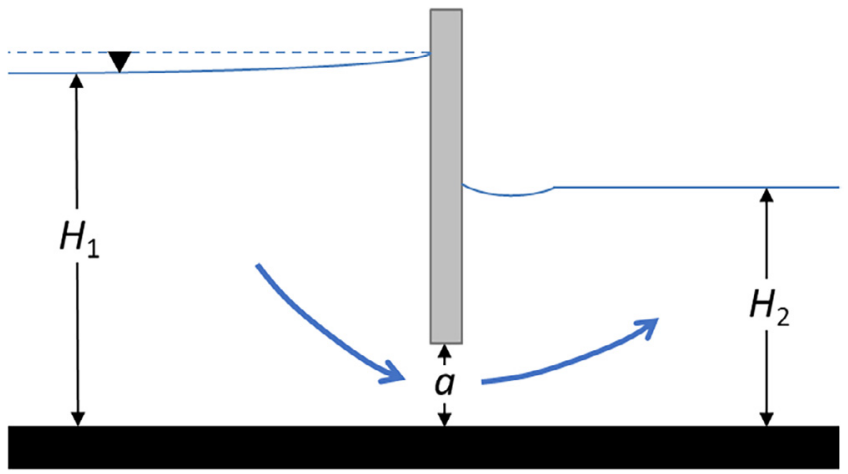

Fig. 5. Variables used in Eqs. (3) and (4) to calculate flow through an undershot weir during drowned conditions.

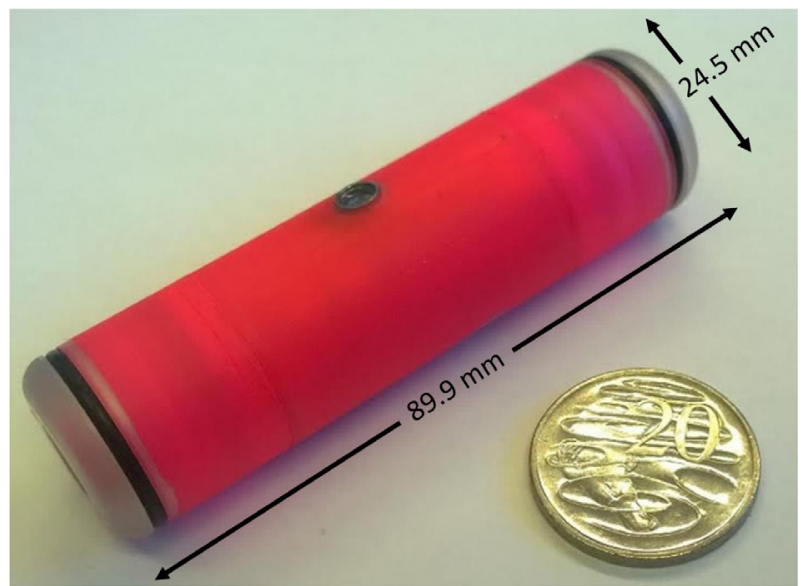

Fig. 6. Gen 2 Sensor Fish next to an Australian twenty-cent coin for scale. Sensor package includes a pressure sensor, three-axis accelerometer, three-axis gyroscope, an orientation sensor, and a temperature sensor, each recorded at a sampling frequency of $2048 \mathrm{~Hz}$ (Deng et al., 2014).

decompression to pressures slightly below atmospheric pressure as it passed between the weir gate and sill (Fig. 9). Pressurisation occurred because Sensor Fish were entrained by the flow to deeper depths prior to passing under the weir gate. The ensuing rapid decompression occurred because the Sensor Fish quickly accelerated under the weir gate and immediately entered shallower water.

Sensor Fish recorded significantly lower nadir pressures $(p<.001)$ when deployed through the undershot weir compared to the overshot weir (Table 1, Fig. 10). Additionally, maximum pressures and maximum RPC were significantly greater $(\mathrm{p}<.001)$ through the undershot weir (Table 1, Fig. 10). Because pressures at both weirs did not drop

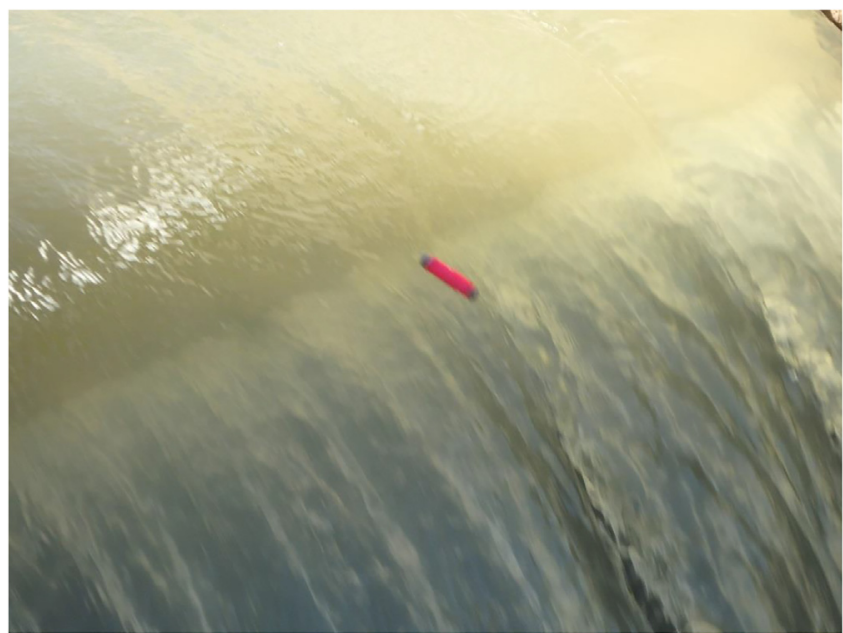

Fig. 7. Sensor Fish were deployed past an overshot weir at Colligen Creek Weir.

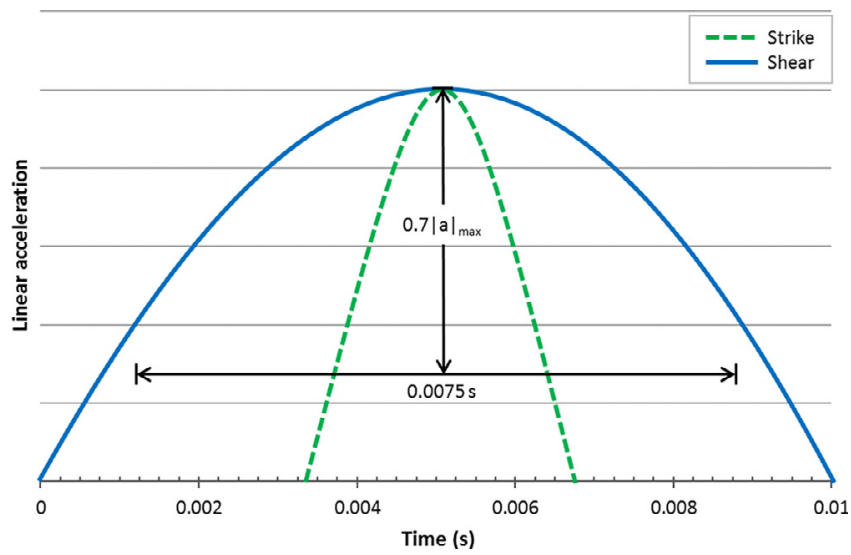

Fig. 8. The difference between a strike and a shear event based on time duration and acceleration amplitude (a). This figure is recreated from Ref. Deng et al. (2007).

much below atmospheric pressure, the minimum RPC would be approximately 1.0 (e.g. $101.4 \div 97.2=1.04$ ). The rate of decompression was only calculated for the undershot weir (Table 1) because a distinct decompression was not evident for Sensor Fish passing the overshot weir (Fig. 9).

\subsection{Strike and shear events}

Strike occurred in most Sensor Fish deployments for both the overshot and undershot weirs. The number of Sensor Fish recording a 


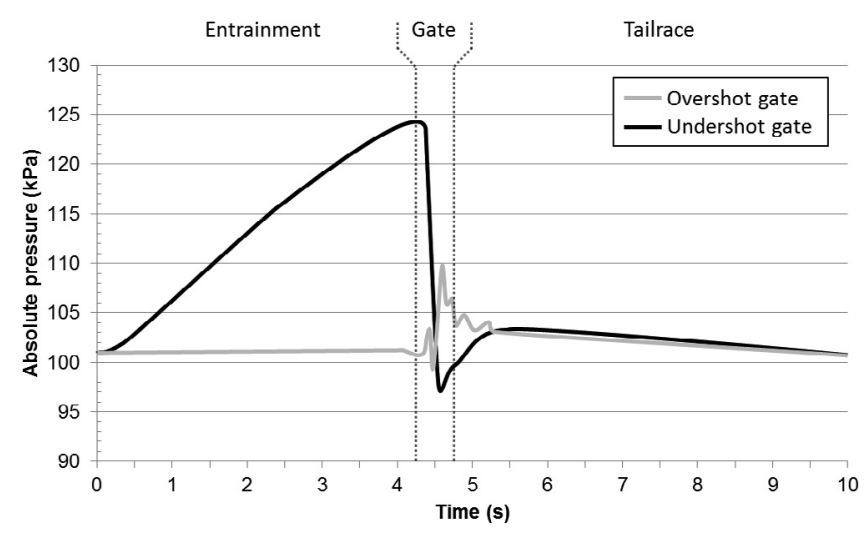

Fig. 9. Sensor Fish data were used to create generalised pressure profiles for both the overshot and undershot weirs at Colligen Creek Weir. Sensor Fish location relative to the structure is labelled above the chart and denoted with vertical dotted lines.

Table 1

Pressure results from Sensor Fish deployed at an overshot weir and an undershot weir at Colligen Creek Weir. ROD refers to the rate of decompression.

\begin{tabular}{|c|c|c|}
\hline Pressure & $\begin{array}{l}\text { Overshot weir } \\
\text { Mean } \pm \text { SD (range) }\end{array}$ & $\begin{array}{l}\text { Undershot weir } \\
\text { Mean } \pm \text { SD (range) }\end{array}$ \\
\hline Nadir $(\mathrm{kPa})$ & $99.1 \pm 0.7(97.7-99.8)$ & $97.0 \pm 1.4(94.7-98.9)$ \\
\hline Maximum $(\mathrm{kPa})$ & $109.8 \pm 3.5(105.5-114.6)$ & $124.2 \pm 2.0(121.7-127.6)$ \\
\hline Maximum RPC & $1.02 \pm 0.01(1.02-1.04)$ & $1.29 \pm 0.02(1.26-1.32)$ \\
\hline $\mathrm{ROD}\left(\mathrm{kPa} \cdot \mathrm{s}^{-1}\right)$ & N/A & $223.2 \pm 26.2(190.1-262.5)$ \\
\hline
\end{tabular}

strike event did not differ $(\mathrm{p}=1.000)$ between the weirs, neither did strike severity $(\mathrm{p}=.803)$, nor the occurrence of multiple strike events during a single deployment $(\mathrm{p}=.400)$ (Table 2, Fig. 11). Shear events were recorded in all deployments at both the overshot and undershot weirs, but shear severity was significantly greater $(\mathrm{p}=.003)$ at the undershot weir (Table 2, Fig. 11).

By cross-referencing acceleration data with the pressure profiles, it was determined that shear events occurred while Sensor Fish passed both weir types. Strike events during passage at the overshot weir predominantly occurred ( $\mathrm{n}=10,83 \%$ of deployments) immediately after $(<0.1 \mathrm{~s})$ entering the plunge pool (Fig. 12). The remaining strike
Table 2

Summary of strike and shear events recorded by Sensor Fish deployed at the overshot and undershot weirs at Colligen Creek Weir. Multiple events are any deployments during which two or more strike events were recorded.

\begin{tabular}{lll}
\hline & Overshot weir & Undershot weir \\
\hline $\begin{array}{l}\text { No. of valid data sets } \\
\text { Strike }\end{array}$ & 12 & 11 \\
$\quad \begin{array}{l}\text { No. of events } \\
\text { No. of multiple events }\end{array}$ & $9(75.0 \%)$ & $10(90.9)$ \\
$\quad \begin{array}{l}\text { Acceleration } \\
\text { Mean } \pm \mathrm{SD}\left(\mathrm{m} \cdot \mathrm{s}^{-2}\right)\end{array}$ & $1245.6 \pm 663.5$ & $7(63.6)$ \\
$\quad$ Range $\left(\mathrm{m} \cdot \mathrm{s}^{-2}\right)$ & $323.8-2208.9$ & $1109.4 \pm 702.7$ \\
Shear & & $317.5-2229.5$ \\
$\quad \begin{array}{l}\text { No. of events } \\
\text { Acceleration }\end{array}$ & $12(100 \%)$ & $11(100 \%)$ \\
$\quad$ Mean $\pm \mathrm{SD}\left(\mathrm{m} \cdot \mathrm{s}^{-2}\right)$ & $119.6 \pm 19.6$ & $165.6 \pm 34.3$ \\
$\quad$ Range $\left(\mathrm{m} \cdot \mathrm{s}^{-2}\right)$ & $81.3-155.8$ & $112.7-209.7$ \\
\hline
\end{tabular}

events occurred approximately $0.5 \mathrm{~s}$ after entering the plunge pool ( $n=2,17 \%$ of deployments). At the undershot weir, most ( $n=8,72 \%$ of deployments) Sensor Fish recorded strike events directly under the weir gate and approximately 1 to $10 \mathrm{~s}$ after passing the weir ( $n=7,64 \%$ of deployments; Fig. 12). One Sensor Fish deployed at the undershot weir recorded a strike event occurring $0.4 \mathrm{~s}$ prior to passage under the weir gate; however, the exact location of this strike could not be determined.

\section{Discussion}

Sensor Fish data supports the observation that the overshot weir is, in general, safer for fish than the undershot weir (Baumgartner et al., 2013; Baumgartner et al., 2006; Marttin and De Graaf, 2002), but both weir designs at Colligen Creek Weir have the potential to injure passing fish due to strike. Sensor Fish recorded strike events as the most severe stressor. Neither occurrence nor magnitude of strike events differed between weir types, but the overshot weir is deemed safer because it had significantly less severe decompression and shear values.

The most likely cause of injury and mortality for fish passing downstream at Colligen Creek Weir is strike. Strike was recorded in a nearly all Sensor Fish deployed at both weirs and reached values known to kill fish (Deng et al., 2010). To date, juvenile Chinook salmon
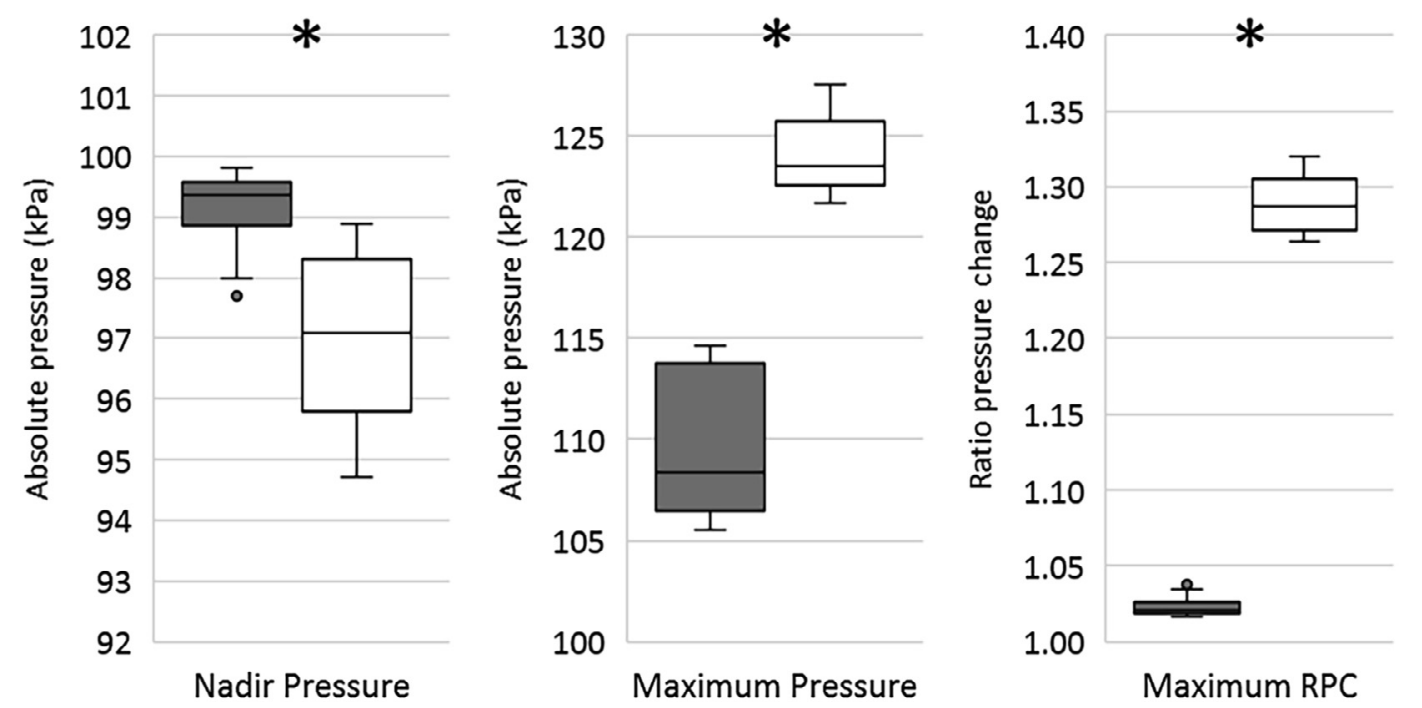

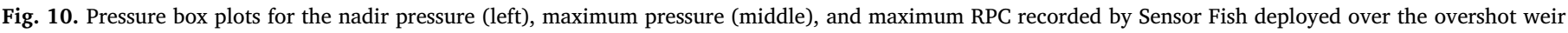

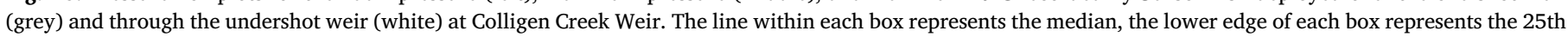

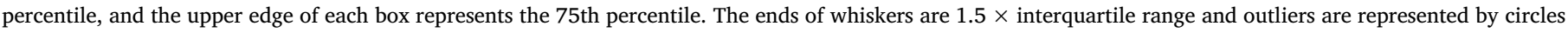
that are filled with the colour corresponding to the designated structure. Significant differences are indicated by the asterisk symbol (*). 

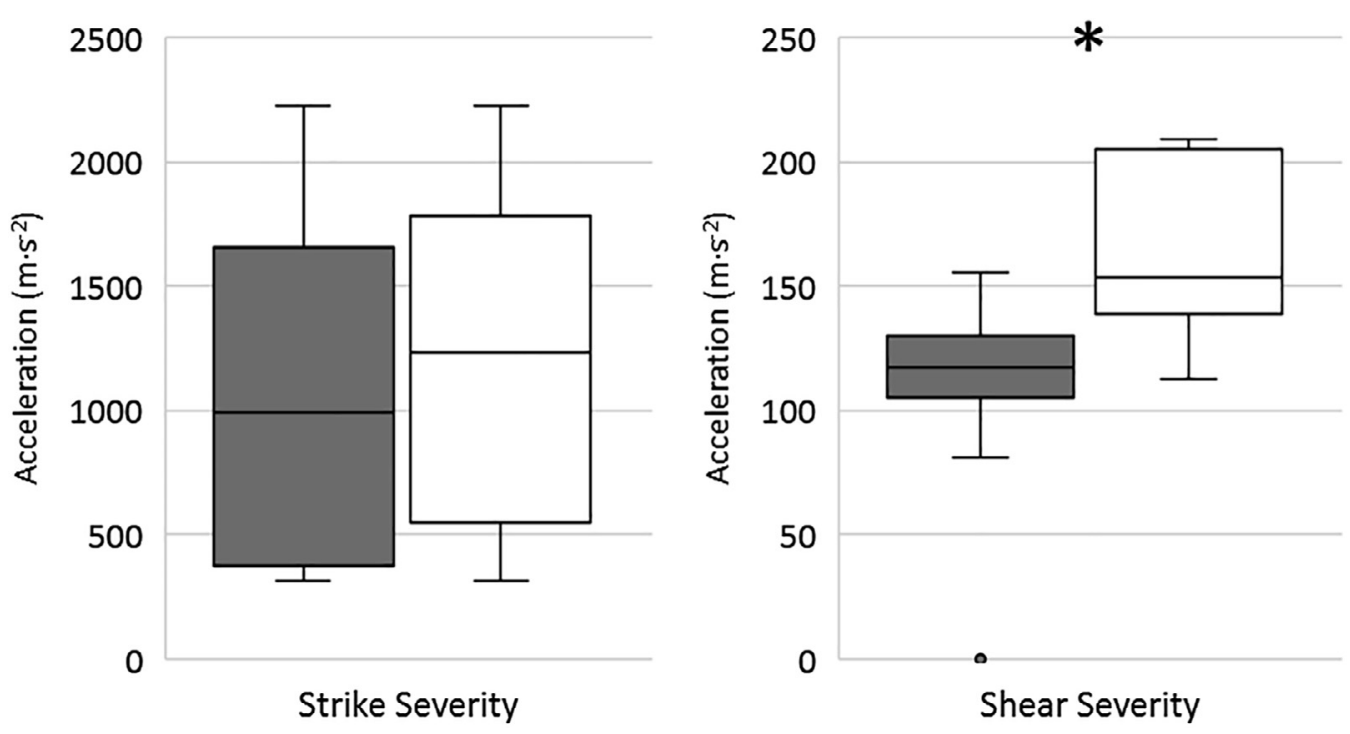

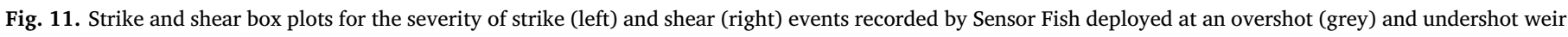
(white) at Colligen Creek Weir. Refer to Fig. 10 for details of box plots.

(Oncorhynchus tshawytscha) are the only fish species for which there is a model for injury and mortality that incorporates acceleration due to strike (Deng et al., 2005). Using this model, the severity of injuries due to strike would likely range from moderate to severe, but most would be severe (78\% for overshot, $50 \%$ for undershot).

The Sensor Fish was designed to understand the physical conditions encountered by fish as they pass through hydroelectric dams. The Sensor Fish is not a live fish and cannot control its body to avoid contact with hydraulic structures. In addition, the mechanisms of live fish being exposed to shear and strike will have major impact on the injury rates, for example, strike to the head will likely lead to higher injury rates than tail collision. However, the Sensor Fish does not distinguish the exposure mechanisms like live fish. Therefore, the percentage of Sensor Fish experiencing significant events will usually be higher than that of live fish. Controlled laboratory and field studies with large sample sizes and live fish would be required to develop does response relationships between the Sensor Fish measurements and live fish injuries. The response relationships may then be used to derive direct biological contexts. Before the dose response relationship is fully established, the data collected using the Sensor Fish is useful for evaluating the relative biological performance of hydraulic structures. For example, for a surface spillway weir evaluated by Duncan et al. (2018), the correlation coefficient between the percentage of the most severe collisions measured by Sensor Fish and live fish injury estimates was $r=0.978$ ( $p=0.0007$ ) and the spillway-deflector region was correctly identified as the issue using Sensor Fish data. After the region was modified, both
Sensor Fish and live fish data showed the fish passage conditions were significantly improved.

Analysis of the measurements made by the Sensor Fish indicates that operating an overshot weir with a plunge pool of insufficient depth is likely to harm fish, as there is a high likelihood that the fish will strike the apron or other submerged objects downstream of the structure. This was reflected in the data obtained at the overshot weir at Colligen Creek Weir. These strike effects could lead to fish injury and death. Not surprisingly, when passing overshot weirs, the mortality of juvenile fish has previously been found to be highly associated with tailwater depth and adult fish have been observed with head wounds suggesting strike on the bottom of the plunge pool (Baumgartner et al., 2013). Modifications have been made to structures to reduce the occurrence of strike on the downstream side of an overshot weir. For example, the Removable Spillway Weir, a type of overshot weir installed at Ice Harbor Dam on the Snake River in south-central Washington State, was modified so that the spillway slope and deflectors would be less likely to injure fish. This redesign was evaluated using Sensor Fish along with a concurrent live fish study which determined that the hydraulic conditions were improved, demonstrating that modifying current structures is a potential method for downstream fish passage (Duncan et al., 2018).

During Sensor Fish deployments, the plunge pool depth at Colligen Creek Weir was $0.7 \mathrm{~m}$, or $40 \%$ of the water level differential, i.e. the difference between the water levels upstream and downstream of the weir. However, a drop board overshot weir, operating with a water

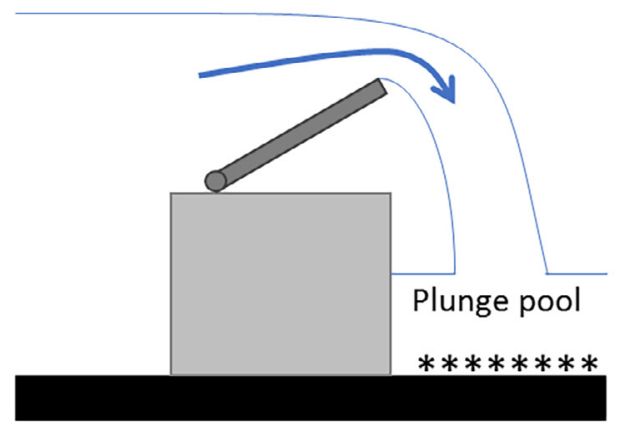

Overshot gate

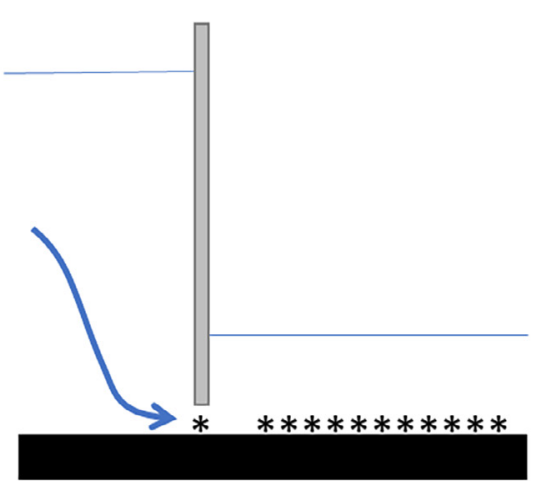

Undershot gate

Fig. 12. Estimations of strike locations (*) for Colligen Creek Weir were determined based on Sensor Fish data. Arrows represent direction of flow. 


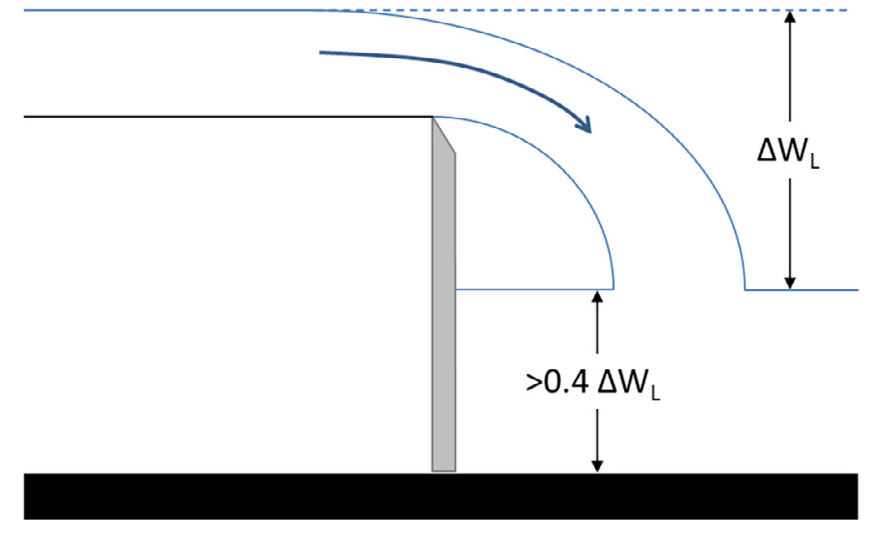

Fig. 13. Plunge pool depth at on overshot weir should be greater than $40 \%$ of the water level differential $\left(\Delta \mathrm{W}_{\mathrm{L}}\right)$.

level differential of $0.7 \mathrm{~m}$ and a plunge pool depth of $0.5 \mathrm{~m}$ (i.e. $\sim 70 \%$ of $0.7 \mathrm{~m}$ ) was found to pass larval fish and cause little mortality (Baumgartner et al., 2006). This suggests that the critical minimum depth of the plunge pool to minimise mortality may exceed $40 \%$ and be less than about $70 \%$ of the water level differential (Fig. 13). Further Sensor Fish testing at overshot weirs with varying plunge pool depths could be carried out in the laboratory to help improve the accuracy of a recommendation for the plunge pool depth beyond a 40-70\% range of water level differential. Currently, recommendations are made to construct new overshot weir structures with a minimum plunge pool depth of $40 \%$ of the water level differential in order to protect fish (MallenCooper, M. pers. comm., 2017), but this is not likely to be sufficient. Based on the findings of this study and others (Baumgartner et al., 2006), it may be more appropriate to apply a more conservative recommendation of $70 \%$ until further testing is completed.

Although strike was an issue at the overshot weir at Colligen Creek Weir, decompression and shear events were not of a magnitude likely to cause injuries to fish (Deng et al., 2005; Pflugrath et al., in press). For barotrauma to occur, fish must be exposed to a severe decompression. This did not occur at the overshot weir because fish must swim close to the surface of the water to pass the weir and pressures remained close to atmospheric pressure, which did not result in a significant decompression. For injuries to occur due to shear exposure, fish must be exposed to turbulent and/or high velocity water, both of which did not occur in the overshot weir.

The undershot weir exposes passing fish to higher levels of decompression than the overshot weir. This is primarily because of the significant differences in maximum pressure. Maximum pressure reflects the maximum depth at which a fish can become acclimated prior to passing the structure and higher values result in greater ratio pressure change. Nadir pressure values were also significantly different between weirs, but, a difference in mean pressures of only $2.1 \mathrm{kPa}$ will minimally alter the ratio of pressure change and likely have very little impact on fish. As a result, ratio pressure change, which combines maximum acclimation pressure and nadir pressure, was significantly greater at the undershot weir, but only because of the differences between acclimation pressures. However, it must be considered that, because ratio pressure change was calculated using the maximum acclimation pressure that is achievable by fish at this weir, it must be regarded as the worst case scenario. Though fish may be able to acclimate to pressures as great as $125 \mathrm{kPa}$ (the pressure at the maximum depth upstream of the undershot weir), in reality, fish may also acclimate to pressures as low as atmospheric (the pressure at the water surface), in which case the ratio pressure change values would not differ between weir types.

Mortality, by exposure to decompression, of fish passing these weir weirs can be predicted from dose-response models. These models have been constructed for various fish species and use ratio pressure change as the predictor variable (Boys et al., 2016a; Boys et al., 2016b; Brown et al., 2012a; Colotelo et al., 2012; Pflugrath et al., in press). These models would predict that no injury or mortality from decompression would occur among fish passing the overshot weir. However, the undershot weir recorded decompression values which in the worst case scenario would could cause about $20 \%$ ( $\pm \sim 7 \%$ ) injury for gudgeons (Hypseleotris spp.) and silver perch (Bidyanus bidyanus) (Pflugrath et al., in press). At these decompression, levels juvenile silver perch have been observed to sustain injuries, such as swim bladder rupture and viscera haemorrhaging (Boys et al., 2016b). Overall, decompression injury and mortality would be expected to be low for both weir types.

Although shear exposure was low for both weir types, fish may still be injured. Response to shear has been examined in several fish species, but as of yet, only one species, juvenile Chinook salmon, has a had a dose-response relationship determined for shear in terms of acceleration and is the only model that can be directly linked to Sensor Fish data (Deng et al., 2005). From the juvenile Chinook model, the mean shear acceleration value of $120 \mathrm{~m} \cdot \mathrm{s}^{-2}$ that was observed in the overshot weir would result in minor injury in about $5 \%$ of fish. The mean shear acceleration value of $180 \mathrm{~m} \cdot \mathrm{s}^{-2}$ observed in the undershot weir would result in about $10 \%$ of fish with minor injury and possibly a few percent of fish with major injuries. Silver perch, golden perch (Macquaria ambigua), and Murray cod (Maccullochella peelii) exposed to shear as egg, larvae, and juveniles were found to be more vulnerable to shear during the earlier life stages (Boys et al., 2014). Therefore, it would be expected that the earlier life stages would have higher injury rates than those predicted for juvenile Chinook salmon. However, shear exposure for silver perch, golden perch, and Murray cod were quantified as strain rate, so a direct estimate of injury and mortality cannot be achieved for Colligen Creek Weir based on Sensor Fish data. Further research is necessary to associate shear exposure, quantified as acceleration, to injury or mortality for additional species and life stages of fish.

Care must be taken when applying the results found for these weirs. Different operational settings and different size scales can alter the hydraulic conditions immensely. For undershot weirs, decompression and shear will likely increase with higher head differentials between upstream and downstream. This is because the decompression observed at the weir is a result of the upstream head and the immediate reduction in head on the downstream side. Additionally, increased head will generally result in increased water velocities under the weir gate, thereby exposing fish to elevated shear stresses.

Although strike is of concern for overshot weirs, it can likely be easily remedied, and, due to the very low likelihood of fish suffering injuries due to shear and decompression, the overshot weir should be considered as the safer alternative to an undershot weir for low-head structures. Additionally, by associating these measurements with previously developed injury and mortality models, estimations of injury and mortality can be obtained for specific fish species. Estimates, such as this, can assist in managing existing hydraulic structures and contribute to future hydraulic structure designs to reduce or eliminate negative impacts on fish.

\section{Acknowledgments}

The authors thank Anthony Fowler and Joseph Clarke of New South Wales Department of Primary Industries Fisheries for their assistance with Sensor Fish deployments and recovery. The authors also thank New South Wales State Water for access and assistance with operation of Colligen Creek Weir.

This work was supported by the Australian Centre for International Agricultural Research.

\section{References}

Baumgartner, L.J., McPherson, B., Doyle, J., Cory, F., Cinotti, N., Hutchison, J., 2013. Quantifying and mitigating the impacts of weirs on downstream passage of native fish 
in the Murray-Darling Basin. Fisheries Final Report. Narrandera, NSW: NSW Department of Primary Industries.

Baumgartner, L.J., Reynolds, N., Gilligan, D.M., 2006. Mortality of larval Murray cod (Maccullochella peelii peelii) and golden perch (Macquaria ambigua) associated with passage through two types of low-head weirs. Mar. Freshw. Res. 57, 187-191.

Boys, C.A., Navarro, A., Robinson, W., Fowler, A.C., Chilcott, S., Miller, B., Pflugrath, B. D., Baumgartner, L.J., McPherson, J., Brown, R.S., Deng, Z.D., 2014. Downstream fish passage criteria for hydropower and irrigation infrastructure in the Murray-Darling Basin. Fisheries Final Report: NSW Department of Primary Industries.

Boys, C.A., Robinson, W., Miller, B., Pflugrath, B.D., Baumgartner, L., Navarro, A., Brown, R.S., Deng, Z.D., 2016a. How low can they go when going with the flow? Tolerance of egg and larval fishes to rapid decompression. Biol. Open:bio., 017491.

Boys, C.A., Robinson, W., Miller, B., Pflugrath, B.D., Baumgartner, L.J., Navarro, A., Brown, R.S., Deng, Z.D., 2016b. A piecewise regression approach for determining biologically relevant hydraulic thresholds for the protection of fishes at river infrastructure. J. Fish Biol. 88, 1677-1692.

Brown, R.S., Carlson, T.J., Gingerich, A.J., Stephenson, J.R., Pflugrath, B.D., Welch, A.E., Langeslay, M.J., Ahmann, M.L., Johnson, R.L., Skalski, J.R., Seaburg, A.G., Townsend, R.L., 2012a. Quantifying mortal injury of juvenile Chinook salmon exposed to simulated hydro-turbine passage. Trans. Am. Fish. Soc. 141, 147-157.

Brown, R.S., Pflugrath, B.D., Colotelo, A.H., Brauner, C.J., Carlson, T.J., Deng, Z.D., Seaburg, A.G., 2012b. Pathways of barotrauma in juvenile salmonids exposed to simulated hydrotrubine passage: Boyle's law vs Henry's law. Fish. Res. 121-122, $43-50$.

Čada, G.F., 1997. Shaken, Not Stirred: The Recipe for a Fish-Friendly Turbine. Waterpower: American Society Civil Engineers.

Čada, G.F., 2001. The development of advanced hydroelectric turbines to improve fish passage survival. Fisheries 26, 14-23.

Colotelo, A.H., Pflugrath, B.D., Brown, R.S., Brauner, C.J., Mueller, R.P., Carlson, T.J., Deng, Z.D., Ahmann, M.L., Trumbo, B.A., 2012. The effect of rapid and sustained decompression on barotrauma in juvenile brook lamprey and Pacific lamprey: implications for passage at hydroelectric facilities. Fish. Res. 129-130, 17-20.

Deng, Z., Carlson, T.J., Duncan, J.P., Richmond, M.C., Dauble, D.D., 2010. Use of an autonomous sensor to evaluate the biological performance of the advanced turbine at Wanapum Dam. J. Renewable Sustainable Energy 2, 053104.

Deng, Z., Lu, J., Myjak, M.J., Martinez, J.J., Tian, C., Morris, S.J., Carlson, T.J., Zhou, D., Hou, H., 2014. Design and implementation of a new autonomous sensor fish to support advanced hydropower development. Rev. Sci. Instrum. 85, 115001.

Deng, Z.D., Carlson, T.J., Duncan, J.P., Richmond, M.C., 2007. Six-degree-of-freedom sensor fish design and instrumentation. Sensors 3399-3415.

Deng, Z.D., Guensch, G.R., McKinstry, C.A., Mueller, R.P., Dauble, D.D., Richmond, M.C., 2005. Evaluation of fish-injury mechanisms during exposure to turbulent shear flow. Can. J. Fish. Aquat. Sci. 62, 1513-1522.

Duncan, J., Deng, Z., Arnold, J., Fu, T., Trumbo, B., Carlson, T., Zhou, D., 2018. Physical and ecological evaluation of a fish-friendly surface spillway. Ecol. Eng. 110, 107-116.

Fu, T., Deng, Z.D., Duncan, J.P., Zhou, D., Carlson, T.J., Johnson, G.E., Hou, H., 2016. Assessing hydraulic conditions through Francis turbines using an autonomous sensor device. Renewable Energy 99, 1244-1252.

Garde, R.J., 1997. Fluid Mechanics Through Problems. New Age International, Daryaganj, New Delhi.

Hou, H., Deng, Z.D., Martinez, J.J., Fu, T., Duncan, J.P., Johnson, G.E., Lu, J., Skalski, J.R., Townsend, R.L., Tan, L., 2018. A hydropower biological evaluation toolset (HBET) for characterizing hydraulic conditions and impacts of hydro-structures on fish. Energies 11, 990.

Marttin, F., De Graaf, G., 2002. The effect of a sluice gate and its mode of operation on mortality of drifting fish larvae in Bangladesh. Fish. Manage. Ecol. 9, 123-125.

Pflugrath, B.D., Boys, C.A., Cathers, B., in press. Predicting river infrastructure induced barotrauma in four Australian fish species.

Schilt, C.R., 2007. Developing fish passage and protection at hydropower dams. Appl. Animal Behav. Sci. 104, 295-325. 